Avrupa Bilim ve Teknoloji Dergisi

Sayı 18, S. 1012-1025, Mart-Nisan 2020

(C) Telif hakkı EJOSAT'a aittir

Derleme Makale
European Journal of Science and Technology

No. 18, pp. 1012-1025, March-April 2020

Copyright (C) 2020 EJOSAT

Review Article

\title{
Deep Learning for Communication Systems
}

\author{
Mete Yıldırım ${ }^{1 *}$, Radosveta Sokullu ${ }^{2}$, Saliha Pehlivan ${ }^{3}$ \\ ${ }^{1}$ Ege Üniversitesi, Mühendislik Fakültesi, Elektrik-Elektronik Bölümü, İzmir, Türkiye (ORCID: 0000-0001-6335-4752) \\ 2 Ege Üniversitesi, Mühendislik Fakültesi, Elektrik-Elektronik Bölümü, İzmir, Türkiye (ORCID: 0000-0002-3544-0319) \\ ${ }^{3}$ Freelance Researcher, İzmir, Türkiye (ORCID: 0000-0001-6299-4424)
}

(First received 25 January 2020 and in final form 15 April 2020)

(DOI: $10.31590 /$ ejosat.679929)

ATIF/REFERENCE: Y1ldırım, M., Sokullu, R. \& Pehlivan, S. (2020). Deep Learning for Communication Systems. European Journal of Science and Technology, (18), 1012-1025.

\begin{abstract}
Deep learning has become the most successful learning method in machine learning. While deep learning provides a clear advantage over other machine learning methods, especially when the amount of data is high, it can produce an approximate result to other machine teaching methods when data is low. This new learning method has the potential to contribute to many innovations, from redesigning the physical layers used in communication technologies to modeling wireless networks. It is particularly useful in communication systems where mathematical modeling is difficult, for example, $5 \mathrm{G}$ and molecular communication. Therefore, many types of research on the application of deep learning in communication systems have been conducted recently. However, the distance of institutions and researchers about communication technologies to deep learning methods has limited the number and impact of these studies. Therefore, it is necessary to collectively examine the studies that involve the application of deep learning to communication technologies, to evaluate the achievements, and to contribute to the determination of new research topics. For this purpose, in this study, firstly, the achievements of deep learning and usage areas are summarized and then the studies that contribute to the development of communication technologies are classified and examined comparatively. To make deep learning more effective in communication, what needs to be done were discussed and deep learning based research areas that could lead to next generation communication systems were determined.
\end{abstract}

Keywords: Communication, Deep learning, Machine Learning, Intelligent communication, Wireless Communication.

\section{Haberleşme Sistemlerinde Derin Öğrenme}

\section{$\ddot{O} \mathbf{z}$}

Makine öğreniminde derin öğrenme en başarılı öğrenme yöntemi olmuştur. Derin öğrenme özellikle veri miktarının çok olduğu durumlarda diğer makine öğrenimi yöntemlerine açık ara üstünlük sağlarken, verinin az olduğu durumlarda diğer makine öğrenim yöntemlerine yakın bir sonuç üretebilmektedir. Bu yeni öğrenme yöntemi haberleşme teknolojilerinde kullanılan fiziksel katmanların yeniden tasarlanmasından telsiz ağların modellenmesine kadar birçok yeniliğe katkı sunacak potansiyele sahiptir. Özellikle matematiksel modellemesi zor olan haberleşme sistemlerinde, örneğin $5 \mathrm{G}$ ve moleküler haberleşme, kolaylık sağlamaktadır. Bundan dolayı derin öğrenmenin haberleşme sistemlerininde uygulanmasını konu alan birçok araştırma son zamanlarda yapılmaktadır. Buna rağmen haberleşme teknolojileriyle ilgili kurum ve araştırmacıların derin öğrenme yöntemlerine olan uzaklığı bu çalışmaların sayısını ve etkisini sınırlı bırakmıştır. Bu sebeple derin öğrenmenin haberleşme teknolojilerine uygulamasını konu alan çalışmaların toplu olarak incelenmesi, elde edilen başarıların değerlendirilmesi, yapabilecek yeni araştırma konularının belirlenmesine katkı sunacak çalışmalara gerek duyulmaktadır. Bu amaca yönelik olarak bu çalışmada öncelikle derin öğrenme yöntemi, başarıları ve kullanım alanları özetle

*Mete Yıldırım: Ege Üniversitesi, Mühendislik Fakültesi, Elektrik Elektronik Bölümü, İzmir, Türkiye, ORCID: 0000-0001-6335-4752), meteyildirim2005@gmail.com 
sunuldu ve haberleşme teknolojilerinin gelişmesine katkı sunan çalışmalar sınıflandırılarak karşılaştırmalı incelendi. Derin öğrenmenin haberleşmede daha başarılı kullanımı için yapılması gerekenler tartışıldı ve yeni nesil haberleşme sistemlerine öncülük edebilecek derin öğrenme tabanlı araştırma alanları belirlendi.

Anahtar Kelimeler: Haberleşme, Derin öğrenme, Makine Öğrenimi, Telsiz Haberleşme, Akıllı Haberleşme

\section{Giriş}

Haberleşme bir bilginin bir noktadan başka bir noktaya fiziksel bir ortam üzerinden taşınması olarak tanımlanabilir. Bu fiziksel ortam kanal olarak adlandırılır (örneğin metal kablolar, hava, boşluk, fiber kablo, kimyasal ortam v.b). Kanallar genelde sinyal üzerinde olumsuz etki oluşturur. Bu olumsuz etkinin sebebi çok çeşitli nedenlerden kaynaklanabilir. Termal gürültü (thermal noise), farklı kaynaklardan doğan sinyal girişimleri (intereference), çok yollu sönümleme (multipath fading) başta olmak üzere birçok yapay veya doğal istenmeyen sinyaller bunlardan sayılabilir. Bu alanın uzman veya araştırmacıları bu etkileri ortadan kaldıracak veya haberleşmenin en azından sağlıklı bir şekilde gerçekleşmesini sağlayacak yöntemler üzerinde çalışma yaparlar. Bu çalışmalar genellikle bazı matematiksel modeller üzerine kurulur. Bu yaklaşım ise gerçek fiziksel yapıdan oldukça uzaktır. Gerçek fiziksel ortam birçok zaman bu etkilerin aynı anda haberleşmeyi etkileyebileceği ortamlardır. Tüm bu etkileri dikkate alacak matematiksel modelleme ise ortaya çıkan girift yapıdan dolayı çok zor ve bazende imaknsızdır. Mobil haberleşmenin ve nesnelerin interneti gibi teknolojilerin (örneğin firsatçı-opportunist, işbirlikçi-cooperative, bilişsel-congitive) gelişimide bu karmaşıklığı çok daha fazla artırmaktadır. Sonuç olarak matematiksel modellenmesi imkansız kanal yapıları türemektedir. Ayrıca kimyasal kanallar ve 5G'nin kullanacağı yüksek frekanslı kanallarda bu tür kanallardan sayılır(Diamandis, 2017). Her ne kadar matematiksel modellemelere dayanan çalışmalar ve onlara dayalı geliştirilen haberleşme teknolojileri çok tatmin edici başarılara imza atarak Shannon'un koymuş olduğu üst limite yakın haberleşme imkanı sağlamış olsalarda donanımsal karmaşıklığın ve bunun neticesinde ortaya çıkan yüksek maliyetin önüne geçememişlerdir. Bununla birlikte haberleşmenin kalitesine artıracak araştırmaların etkisinin ise giderek azaldığı gözlemlenmektedir. Ayrıca doğrusal olmayan etkilerle Shannon limitinin üstünde bir kapasite için yapılan çalışmalarda çok karmaşık modeller gerektireceğinden matematiksel modellemeye ihtiyaç duymayan haberleşme modellerinin geliştirilmesi önemli olmuştur (Sorokina \& Turitsyn, 2014). Şüphesiz bu yöntemlerin başında son zamanların birçok çalışmasında adından sıkça söz edilen, her alanı etkisi altına alan, bununda ötesinde farklı çözüm yaklaşımları geliştiren ve belkide sanayi devriminin yaptığı etkiyi tekrar yaşattıracak günümüzün en çok çalışılan konularından olan Derin Öğrenme (DL - Deep Learning) gelmektedir.

Bu çalışma DL yönteminin haberleşme sistemlerine uygulanabilirliğini yönelik güncel çalışmaları incelerek, haberleşme için yeni alternatif yöntemler ortaya koyan bu yaklaşımın pozitif ve negatif sonuçlarını ortaya koymayı ve yeni araştırmalar için bir yol haritası belirlemeyi amaçlamaktadır. Bunun için çalı̧̧manın birinci bölümde kısaca DL'e değinilmiş, ikici bölümde derin öğrenmenin haberleşme uygulamaları alt bölümler halinde incelenmiş ve son bölümde yapılan çalışmalardan elde edilen kazanımlar değerlendirilerek araştırma yol haritası çıkarılmıştır.

\section{Derin Öğrenme}

Yapay zeka ile çözülmesi çok zor olan problemlerin çözülmesinde çok büyük bir katkı yapan DL makine öğrenme yöntemlerinden biri olmasına rağmen görüntü, ses ayırt etme, dil çevirisi yapma, doğal konuşma anlama, konu sınıflandırma, soru cevaplama vb. birçcok alanda diğer makine öğrenme tekniklerine çok büyük bir üstünlük sağlamıştır (LeCun, Bengio, \& Hinton, 2015). En önemli özelliği ise ham bilgiyi doğrudan işleyebilmesidir(Goodfellow, Bengio, Courville, \& Bengio, 2016). Bu öğrenme yöntemleri genel olarak ilk katmandan son katmana doğru ham bilginin her katmanda bulunan çok sayıda doğrusal olmayan karar vericiler tarafından işlenip birleştirilmesinden oluşmaktadır. Makine öğrenimi genelde denetimli, denetimsiz ve yarı denetimli olmak üzere üçe ayrılır. Denetimli öğrenme eldeki sınıflandırılmış bilgiye dayanarak öğrenme yapan makinenin, ilk defa karşılaş̧ı̆̆ verebilmesidir. Örneğin bazı nesnelerin resimleri ile eğitilen makine yeni bir resimle karşılaşıı̆ı̆nda bu resmi ayırt edebilir (Şekil 1).

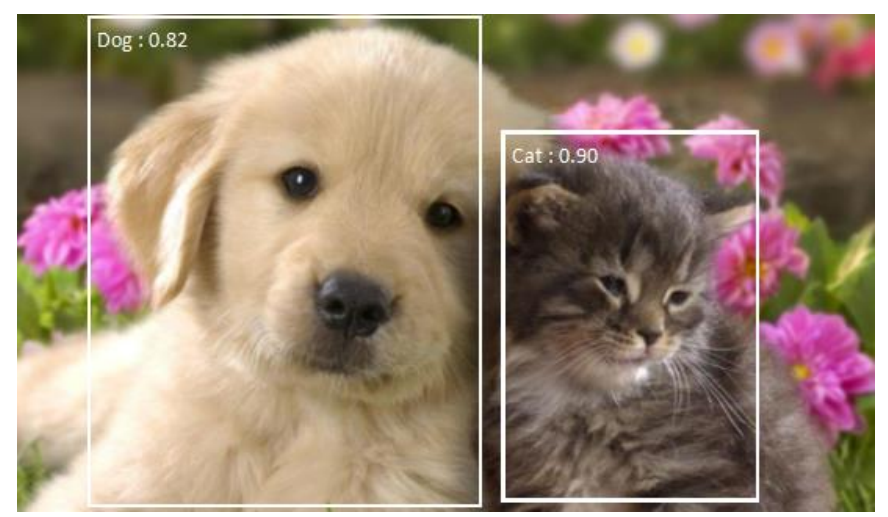

Şekil 1. Derin ögrenme ile gerçek zamanlı nesne algılama 
Sınıflandırılmış bilgiden kasıt makinin ayırt etmesi istenen nesnelerden oluşan bir veri tabanıdır. Bu veri tabanında hangi nesnenin ne olduğu belirtilmiştir. Bu verilere dayanarak bir öğrenimden geçirilen makineninde yeni bir nesne ile karşılaştığında bunun en yüksek olasılıkla ne olduğunu bilmesi beklenir ve bu denetimli öğrenim olarak adlandırılır. Örneğin Şekil 1'de makine nesneleri olasılıklarına belirterek tanımlamıştır. Amaç en yüksek olasılıkla doğru seçimi yapmak olduğu için sistem iç parametrelerini yeniden ayarlayarak tahmindeki hatayı düşürmeye çalışır. Yani hatadan ders çıkarılarak öğrenme yapılır. Bu parametreler ağırlık olarak adlandırılır ve bir katmanın giriş ile çıkış arasındaki ilişki oranını belirtirler. Peki hatayı düşürmek için bu parametreler nasıl ayarlanmalıdır? Aslında parametrelerin ayarlanması zincirleme türevin bir uygulamasıdır. Öncelikle her katmandaki ağıllı̆̆ın en son değeri ne kadar etkilediği bulunur. Bu hesaplama en son katmandan ilk katmana doğru yapılır. Örneğin son katmanadaki ağırlıklar sonucu nasıl etkilemiştir bulunur. Sonra sondan ikinci katmana gelen ağırlıklar sonucu nasıl etkilemiştir hesaplanır. Tahmindeki hatanın en aza indirilmesi için bu ağırlıklar etkileme oranları kadar ters yönde değiştirilir ve bu en iyi tahmin yapılana kadar devam ettirilir. Özetle en nihayi sonucun bütün katmalardaki ağırlıklar tarafından ne kadar etkilendiğinin hesaplanması ve bu miktarda ters yönde değiştirilmesi ile yeni hesaplama yapılır. Veri tabanındaki her örnek için bu hesaplama yapılarak ağıllıklar için ortalama değer bulunur. Bulunan bu ortalama değer sistemin öğrenimini tamamladığı anlamına gelmektedir ve yeni durumlarda karar verebilmek için kullanılanılır.

Denetimsiz öğrenmede ise etiketlenmiş bilgi söz konusu değildir. Sadece gruplanmamış ham bilgi vardır. Makineden bu sınıflandırılmamış bilgilerden sınıflandırma yapması beklenir. Bu sınıflandırma herhangi bir veya birkaç özelliğe göre olabilir. Denetimsiz öğrenme şimdiye kadar yapılan çalışmalarda denetimli öğrenmenin gerisinde kalmasına rağmen gelecekte çok daha fazla etkili olacağı beklenmektedir. Bunun sebebi ise insanın daha çok bu şekilde öğrenmesidir. Örneğin otokodlayıcı (AE-Autoencoder) önemli bir denetimsiz öğrenme yöntemidir ve haberleşme sistemleri dahil birçok uygulaması vardır(G. E. Hinton \& Salakhutdinov, 2006). Şekil 2'de görüldüğü gibi uç uca eklenmiş iki yapay sinir ağını andıran bu öğrenme yöntemi ile bir resim kodla-kodçöz (encodedecode) işlemin uygulanarak yeniden oluşturulmuştur. Bu tıpkı haberleşmede olduğu gibi bilginin bir noktadan başka bir noktaya transfer edilerek yeniden oluşturulmasına benzetilebilir. Çünkü haberleşmede de bir bilgi aslında başka bir noktaya iletilmememekte ama hedef noktada yeniden yapılmaktadır. Bu durumda AE yapısı verici-alıcı dahil tüm haberleşme bloklarının tek bir yapı olarak düşünüldüğü uçtan-uca(end-to-end) tam bir haberleşme sistemi gibi değerlendirilebilir.

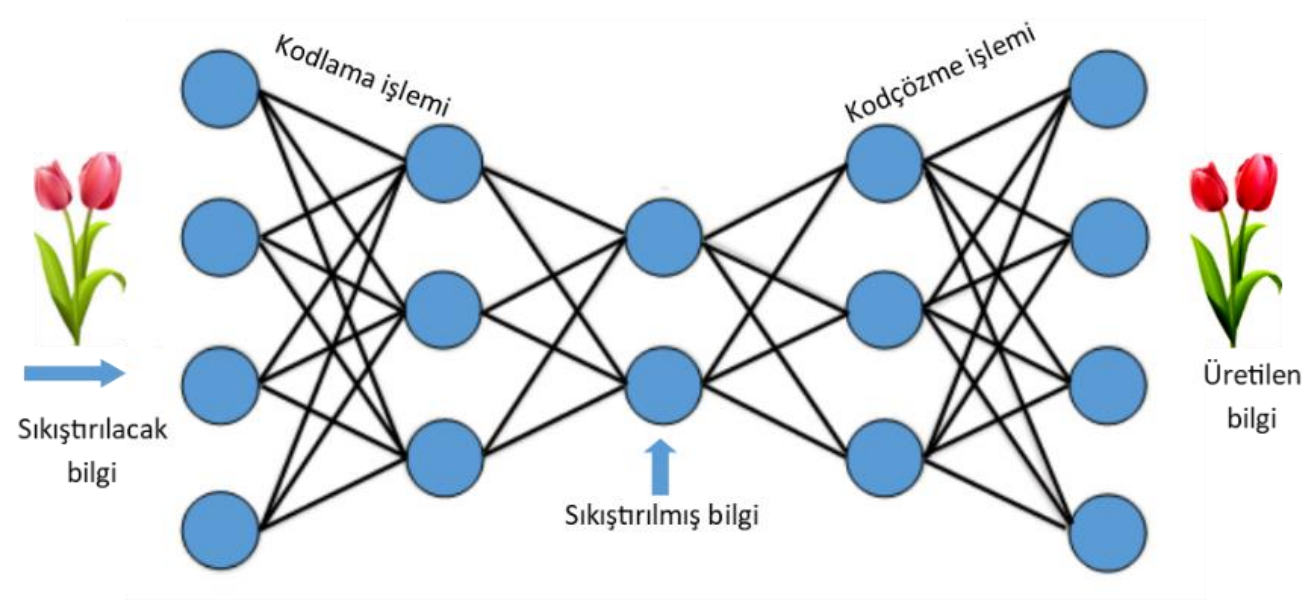

Şekil 2. Otomatik kodlayıcı kullanılarak orjinal bilgi (sol lale resmi) sıkıştırılmış şekilde saklanması ve daha sonra bu bilgiden orjinal bilgiye çok yakın bilgi (sağ lale resmi) yeniden yapılması

DL’nin farklı uygulamalar için öne çıkan farklı yapıları vardır. Bu DL yöntemleri konvansiyonel sinir ağları (CNN- Convolutional Neural Network), tekrarlanabilir sinir ağları (RNN-Recurrent Neural Networks), sınırlı boltzman makinesi (RBM- Restricted Boltzmann Machines), derin inançlı ağlar (DBN- Deep Belief Networks), otomatik kodlayıcı (AE- Autoencoders), üretken rakip ağlar (GAN - Generative Adversarial Nets) olarak sayılabilir.

Derin öğrenmeye sahip olduğu şöhreti kazandıran büyük öneme sahip dönüm noktası niteliğinde çalışmalar vardır. (Goodfellow et al., 2016) makine öğrenimi ile genel bir bilgi sunan ve özellikle DL’ye yönelik hazırlanmış internet ortamında herkese açık önemli bir kaynak kitaptır. (LeCun et al., 2015) ise DL'ye yönelik hazırlanmış en önemli inceleme makalelerinden biri olarak değerlendirilebilir. (G. E. Hinton, Osindero, \& Teh, 2006) ve (G. E. Hinton \& Salakhutdinov, 2006) derin inançlı ağlara (DBN) yönelik en önemli çalışmalardandır. (Krizhevsky, Sutskever, \& Hinton, 2012; Szegedy et al., 2015) çalı̧̧maları görsel sınıflandırmaya yönelik önemli CNN araştırmalardandır.(G. Hinton et al., 2012), (Graves \& Jaitly, 2014), (Sak, Senior, Rao, \& Beaufays, 2015), (Amodei et al., 2016) ve (Xiong et al., 2016) ise RNN kullanarak konuşma tanıma için önemli makalelerdendir. (G. E. Hinton, Srivastava, Krizhevsky, Sutskever, \& Salakhutdinov, 2012), (Srivastava, Hinton, Krizhevsky, Sutskever, \& Salakhutdinov, 2014), (Ioffe \& Szegedy, 2015), (Ba, Kiros, \& Hinton, 2016), (Jaderberg et al., 2017) ise DL için oluşturulacak modellerin verimliliğini artırmak için yapılan en önemli araştırmalardandır. (Kingma \& Ba, 2014)ve Ba (2014), (Andrychowicz et al., 2016)(Han, Mao, \& Dally, 2016) ise tasarlanan modelin 
optimizasyonu hedefleyen en önemli eserlerdendir. Makinelere insan gibi bir control kazandırmayı hedefleyen önemli derin öğrenme takviyeli (DRL) çalışmaları arasında ise (Mnih et al., 2015), (Silver et al., 2016) ve (Silver et al., 2016) kabul edilir. Bazı araştırmacılara göre belkide son on yılın en önemli makine öğrenimi olarak değerlendirilen GAN için, (Goodfellow et al., 2014) ilk çalışmadır.

Derin öğrenme için kullanılan modelin bir programlama dilinde oluşturulması gerekir. Bunun için birçok programla dili kullanılabilir. Hazır modüller içeren, Keras, TensorFlow, Caffe vb. çerçeve programlarda kullanılabilir. Anaconda tüm bu programların kullanılabileceği bir platformdur. Eğer çevrimiçi çalışılmak isteniyorsa Google ait Colab bu hizmeti ücretsiz GPU ve TPU desteği ile beraber sunmaktadır. Pratik amaçlı birçok veri bankası Kaggle'dan ücretsiz alınabilir. Bununla birlikte telsiz haberleşmeye yönelik birkaç veri bankası Deepsig'de sunulmaktadır.

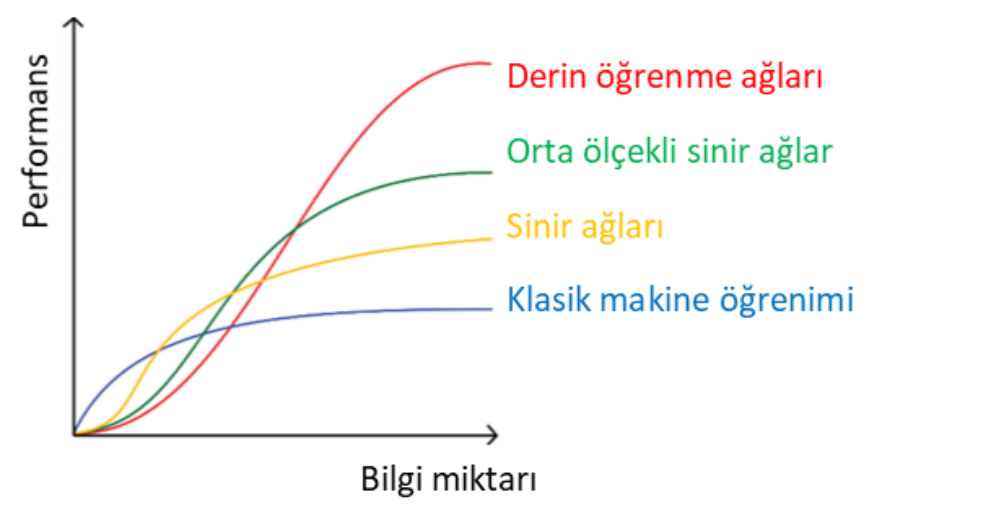

Şekil 3. Öğrenme metotlarının bilgi miktarına göre performansları

Tablo 1. Bölümler halinde DL'nin haberleşme uygulamaları

\begin{tabular}{|c|c|}
\hline Makale & Konusu \\
\hline $\begin{array}{l}\text { (West \& O’Shea, 2017), (T. J. O’Shea, Corgan, \& Clancy, n.d.; T. J. O’Shea \& Corgan, } \\
\text { 2016), (Ramjee et al., 2019), (J. H. Lee, Kim, Kim, Yoon, \& Choi, 2017), (Zhang et al., } \\
\text { 2018), (Chikha, Dayoub, Hamouda, \& Attia, 2014), (Yashashwi, Sethi, \& Chaporkar, } \\
\text { 2019), (Mendis, Wei, \& Madanayake, 2019), (Liu, Yang, \& Gamal, 2017) }\end{array}$ & $\begin{array}{c}\text { Sinyal } \\
\text { Tanıma }\end{array}$ \\
\hline $\begin{array}{l}\text { (H. Wang et al., 2019), (U. Mohammad \& Sorour, 2018), (Elbaz \& Zibulevsky, 2018), } \\
\text { (Chen \& Laneman, 2006), Ahmad (A. S. Mohammad, Reddy, James, \& Beard, 2018) }\end{array}$ & Modülasyon \\
\hline $\begin{array}{l}\text { (T. J. O'Shea, Karra, \& Clancy, 2016; T. J. O'Shea, Roy, West, \& Hilburn, 2018; T. J. } \\
\text { O'Shea, Roy, \& West, 2018), (Karanov, Lavery, Bayvel, \& Schmalen, 2019), (He, Wen, } \\
\text { Jin, \& Li, 2018a), (Y. Yang, Gao, Ma, \& Zhang, 2019), (Hao Ye, Li, \& Juang, 2018)Ye, } \\
\text { (Soltani, Pourahmadi, Mirzaei, \& Sheikhzadeh, 2019), (Arnold et al., 2019), (Jiang et al., } \\
\text { 2018),(Jiang et al., 2019), (Cheng, Liu, Wang, Yan, \& Zhu, 2019),(Fujihashi, Koike- } \\
\text { Akino, Watanabe, \& Orlik, 2018), (H. Ye \& Li, 2017),(Kang, Chun, \& Kim, 2018),(T. J. } \\
\text { O’Shea, Erpek, \& Clancy, n.d.), (Hao Ye et al., 2018), (Y. Yang, Li, et al., 2019), (Saud } \\
\text { Mobark Aldossari, 2019), (Laura Brink Anant Sahai, 2018) }\end{array}$ & $\begin{array}{l}\text { Kanal } \\
\text { Kestirim, } \\
\text { Eşitlenme }\end{array}$ \\
\hline $\begin{array}{l}\text { (Z. Xu, Wang, Tang, Wang, \& Gursoy, 2017), (U. Mohammad \& Sorour, 2018), (Ahmed, } \\
\text { Tabassum, \& Hossain, 2018), (Reddy, 2006),(Sanguinetti, Zappone, \& Debbah, 2018), } \\
\text { (Nasir \& Guo, 2018), (Kim, Lee, \& Choi, 2018), (Zhou, Fadlullah, Mao, \& Kato, 2018), } \\
\text { (H. Ye, Li, \& Juang, 2019), (H. Li, Gao, Lv, \& Lu, 2018), (J. Li, Gao, Lv, \& Lu, 2018), } \\
\text { (Ahmed et al., 2018), (Zhao, Liang, Niyato, Pei, \& Jiang, 2018), (J. Wang, Zhao, Liu, \& } \\
\text { Kato, 2019), (Hao Ye et al., 2018), (Wu et al., 2019), (T. Yang, ü, Gursoy, Schmeink, \& } \\
\text { Mathar, 2018),(S. Xu, Liu, Wang, \& Panwar, 2018), (Shen, Shi, Zhang, \& Letaief, 2018) } \\
\text { (Guo, Liang, \& Li, 2019) }\end{array}$ & $\begin{array}{c}\text { Kaynak } \\
\text { Paylaşımı } \\
\end{array}$ \\
\hline $\begin{array}{l}\text { (Bourtsoulatze, Kurka, \& Gunduz, 2018), (H. Ye \& Li, 2017), } \\
\text { (Nachmani et al., 2018; Nachmani, Be'ery, \& Burshtein, 2016), (Han et al., 2016), } \\
\text { (Gruber, Cammerer, Hoydis, \& Brink, 2017), }\end{array}$ & Kodlama \\
\hline $\begin{array}{l}\text { (Farsad \& Goldsmith, 2018), (Corlay, Boutros, Ciblat, \& Brunel, 2018), (He et al., } \\
\text { 2018a), } \\
\text { (Samuel, Diskin, \& Wiesel, 2017), (Jia, Cheng, \& Zhang, 2019), } \\
\text { (Al-Baidhani \& Fan, 2019) }\end{array}$ & Deteksiyon \\
\hline
\end{tabular}


Derin öğrenmenin son zamanlarda yaygın kullanılıyor olmasının temel iki sebebi çok büyük kapasitelere sahip hesaplama imkanının oluşması ve çok fazla bilginin erişelebilirliliği olarak değerlendirilebilir. Bu yapı normal nöral ağlara göre (NN) çok fazla katmana sahiptir ve isminide buradan almaktadır. Bu ise yüksek işlem kapasitesi gerektirmektedir. Öyleki mevcut CPU işlem kapasitesinin ötesinde işlem yapabilecek GPU ve son zamanlarda konuşulan TPU bu amaca yönelik geliştirilmiş teknolojilerdir. Bunun yanında DL'nin NN göre üstünlüğü özellikle çok yüksek bilginin erişebilirliliği ile ortaya çıkmaktadır. Şekil 3'de gösterildiği gibi bilginin az olduğu durumlarda DL metodu diğer öğrenmelere yakın bir performans sergilerken bilgi artıkça DL'nin performans farkı oluşturduğu gözlemlenmiştir. Bu daha önce farklı makine öğrenim metotları ile ele alınan problem çözümlerinin yeniden DL ile ele alınmasını gerekli kılmaktadır.

\section{Haberleşmede Derin Öğrenme}

(Ibnkahla, 2000) ve içerdiği kaynaklar makine öğrenimi yöntemlerini kullanarak haberleşme sistemleri birimlerinin gerçekleşterilmesine veya performanslarının artııılmasına yönelik yapılan ilk araştırmalardır. Bunlar modülasyon tipinin tanımlanması, kanal modelleme, kodlama ve çözümleme, kanal kestirimi, kanal eşitleme ve benzeri konuları içermektedir. Bu çalışmalar zamanın makine öğrenimi yöntemlerindeki öğrenme kapasitesinin sınırlılı̆̆ından dolayı ihtiyaç duyulan sonuçları üretememiş ve bunun neticesinde gerçek uygulamalarda yer almamışlardır. Bununla birlikte derin öğrenmenin göstermiş olduğu olağanüstü performansta göz önüne alınırsa bu çalışmaların yeniden yapılması gerekliliği ortaya çıkmaktadır. Ne yazık ki haberleşme alanında araştırmada bulunanların DL'den uzak olması bu çalışmaları sınırlamıştır. Yine de son zamanlarda birçok araştırmacı derin öğrenmenin haberleşme sistemlerine uygulanmasına yönelik çalışmalar yapmış ve klasik yöntemlerin ötesinde performanslar elde etmeyi başarmışlardır. İncelenen bu araştırmalar yapılan çalışmaya göre Tablo.1'de sınıflandırılmıştır.

\subsection{Yeni Modeller}

Bir haberleşme sistemi farklı görevleri yerine getiren alt sistemlerden oluşur. Her alt sistem bir blokla temsil edilir. Bu bloklar belirli bir düzene göre birbirleriyle ilişkilendirilir. Farklı tasarımlarda blokların sıralaması veya sayısı değişiklik gösterse de genelde bir uyum söz konusudur. Bu sayede teknolojinin gelişmesi ile ortaya çıkan ve haberleşmenin kalitesini artıracak yeni bloklar sisteme kolayca entegre edilebilmektedir. Örneğin ilk haberleşme sistemlerinde bugün kullandığımız kaynak kodlama, kanal kodlama, şifreleme, çoğullama, kanal eşitleme gibi birçok alt sistem yer almamıştır. Daha çok sayısal haberleşmenin gelişmesi ile ortaya çıkan bu sistemlerde kendi içinde başka alt sistemlere ayrılabilmektedir. Buna örnek olarak kaynak kodlamanın örnekleme ve kuantize yapan iki alt sistemden oluşması gösterilebilir. Her sistemden olduğu gibi bir haberleşme sisteminden beklenen de yapım amacına yönelik en optimum sonucu üretmesidir.

$\mathrm{Bu}$ amaca yönelik olarak şimdiye kadar her blok kendi içinde optimum çalışacak şekilde tasarlanmaya çalışılmıştır. Bu tüm yapının en optimum şekilde çalşsacağı anlamına gelmemektedir. Son zamanlarda tüm sistemi tek bir parça olarak düşünüp, tasarlayıp ve optimize yapma gayretleri oluşmuştur. İşte biz bu yaklaşımları yeni modellerin tasarımı olarak sunmayı tercih ediyoruz. Bu yeni model tasarımlarında en son hedef tüm sistemin optimize edilmesi ise de klasik haberleşme sistemlerinde yer alan birkaç bloğun bir arada optimize edilmesi de bu yeni model yaklaşımlarına dahil edilebilir.

Şekil 4'te verilen AE bu amaç için haberleşme sistemlerinde kullanılan en önemli yapılarından biridir. Araştırmalarımız bize AE'nin haberleşmeye yeni tasarım olarak değerlendirilebilecek ilk uygulanmasının (T. J. O’Shea \& Hoydis, 2017) tarafindan yapıldığını göstermiştir. Bu çalışmada çoğunlukla veri sıkıştırmada kullanılan ve her kanalı öğrenme yeteneğine sahip denetimsiz öğrenme algoritmalarından biri olan AE kullanılarak uçtan uca haberleşme sistemi (tüm haberleşme blokları) bir bütün olarak tasarlanmıştır. Bu sistem BPSK modülasyonu kullanılarak AWGN kanalında test edilmiştir. AE’nin performansı, kodlanmış ve kodlanmamış BPSK ile bit hata oranı üzerinden karşılaştırılmıştır. AE tasarımının kodlanmamış BPSK yapısından daha iyi bir sonuç verdiği gözlemlenmiştir. Bununla birlikte AE sistemin esas sorununun sembol sayılarının artması ile modelin eğitilmesinden dolayı ortaya çıktığı belirtilmiştir. Aynı çalışmada uzaysal dönüştürücü ağların (SPN- Spatial Transform Networks) değiştirilmiş bir versiyonu olan ve yapısında AE bulunduran radyo (Şekil 5) dönüştürücü ağlar (RTN- Radio Transformer Networks) önerilmiş ve solmalı kanalda test edilmiştir. Daha az veri ile öğretimi mümkün olan bu yapı ile daha iyi bir performans üstelik solmalı kanalda elde edilmiş ve $20 \mathrm{~dB}$ 'de on kat verim artırılmıştır. Bununla beraber sistem daha girift bir hal almıştır. (Dörner, Cammerer, Hoydis, \& Brink, 2018) bu çalışmayı pratik ortama taşımışıır. Bu çalışmada yazılım tabanlı bir radyo olan USRP kullanılarak sembol girişimi ile senkronizasyon işlenmiştir. (Felix, Cammerer, Dörner, Hoydis, \& Brink, 2018) ise benzer araştırmayı OFDM tabanlı sistemde kullanılarak çok yollu telsiz ortamda AE'nin başarılı olarak kullanılabileceği göstermiş̧tir. (T. J. O'Shea, Erpek, \& Clancy, 2017) AE’nin tek kullanıcılı MIMO sisteminde başarılı şekilde uygulanabileceğini gösterilmiştir.

(H. Wang et al., 2019) gerçek bir kablosuz sisteme derin öğrenme uygulamasına güzel bir örnek oluşturmaktadır. Çalışmada belirtilen gerçek ortam her ne kadar çok farklı özelliklerlere sahip olabilecek telsiz ortamı temsil etmekten uzak olsada, DL'nin gerçek sinyaller üzerine uygulanması adına güzel bir çalışmadır. Oluşturulan sinyaller ayrıca paylaşılarak araştırmacılara farklı yeni çalışma yapma imkanı sunulmuştur. Bu çalışmada alınan sinyalin bir kısmı modelin öğretimi için kullanılmıştır. Her ne kadar bu durum pilot veri kullanarak sinyal elde etmeye benzesede, temelde farklılık göstermekte, çünkü öğretilen model tekrar ek bir bilgiye ihtiyaç duymamaktadır. Bundan dolayı daha başarılı sayılabilir. Ayrıca çalışmada Adaboost adında önerilen model ile bu başarı daha ileriye taşınmış sistem performansı yükselmiştir.

Yeni haberleşme modelleri için önerilebilecek modeller veriye dayalı ve modele dayalı başlıklar altında incelenebilir. Yukarıda bahsedilen modeller daha çok veriye dayalı modellerden oluşmaktadır. Veriye dayalı modeller çok büyük veri miktarı gerektirdiğinden yüksek işlem gücü ve uzun zamana ihtiyaç duyarlar. Bundan dolayı alternatif modele dayalı tasarımlar önerilmiştir. Modele dayalı tasarımlarda haberleşme için kullanılan fiziksel yapı dikkate alınarak daha az veri ile daha az sürede öğretim başarılmaktadır. Modele 
dayalı haberleşme ilgili çalışmalara (He et al., 2018a), (He, Wen, Jin, \& Li, 2018b) örnek olarak verilebilir. He, Jin ve diğ. (2018) modele dayalı alıcı tasarımı önerilirken kanal modelinin tamamen belirsiz olduğu durumlarda veriye dayalı öğrenimin kaçınılmaz olduğu belirtilmiştir. (He et al., 2018b) modele dayalı DL sistemi MIMO’ya uygulanırken rayleigh ve korelasyonlu MIMO kanalda yinelemeli algoritmaların verimliliğini artırmışır.

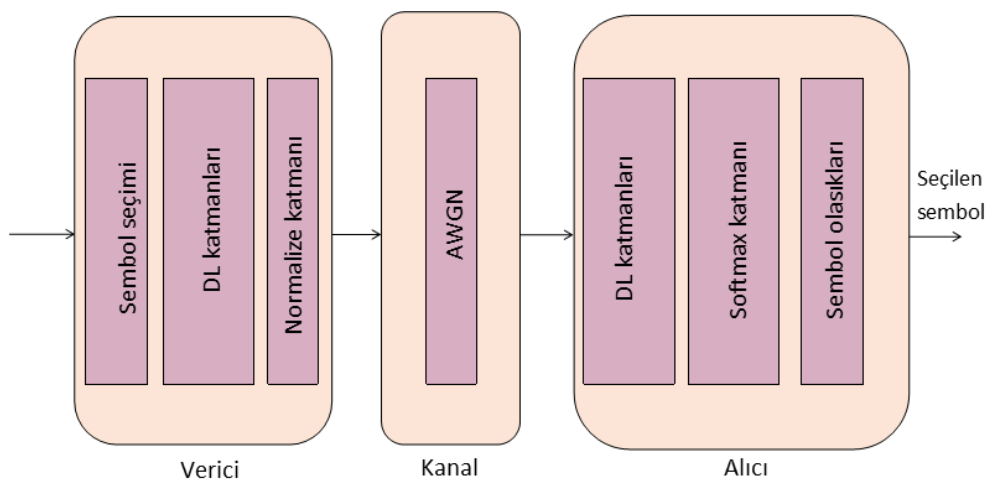

Şekil 4. AE ile uçtan uca haberleşme sisteminin AWGN kanalda tasarımı (O’Shea ve Hoydis, 2017).

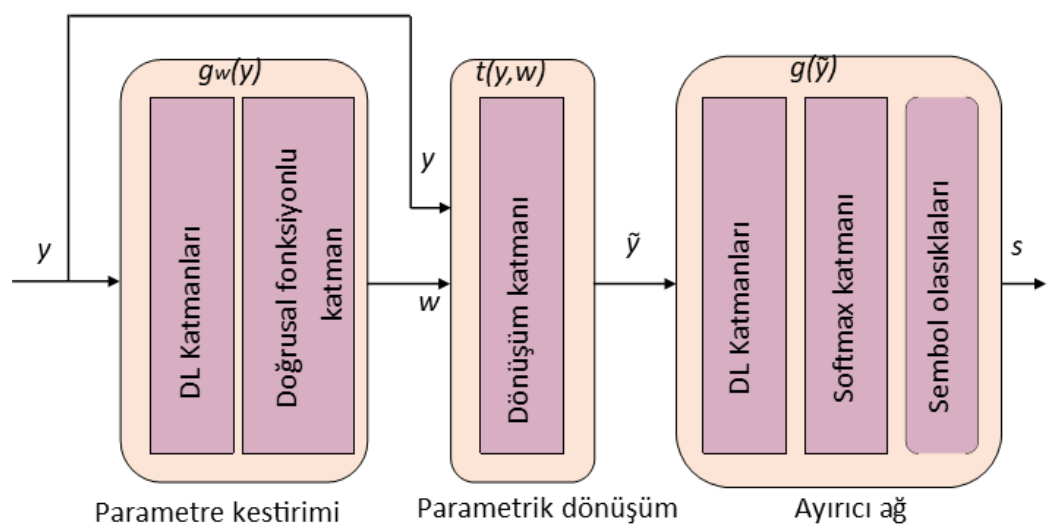

Şekil 5. RTN'nin bir alıcı olarak kullanımı (O’Shea ve Hoydis, 2017).

\subsection{Sinyal ve Modülasyon Tanıma}

Spektrumun verimli kullanılması, istihbarat amaçlı sinyallerin izlenmesi, alıcıların farklı yayın türlerini algılaya bilmesi, yetkili kurumların spekturumu takip etmesi, farklı sinyallerin girişimin engelenmesi ve benzeri gibi birçok sebepten dolayı sinyal ve modülasyon tanımlanmasına gerek duyulabilir. Özellikleri bilinen sinyallerin algılanması kolayken, hiçbir özelliği bilinmeyen sinyallerin algılanması oldukça karmaşık işlemler gerektirebilir.

Dinamik spektrum erişimi sağlayan önemli bir teknoloji bilişsel radyo (CR- Cognitive Radio) olarak bilinir. Sürekli aynı biçimde yayın yapan vericilerden farklı olarak CR düzenli spektrum dinlemesi yaparak iletişim parametrelerini (güç, modülasyon tipi, çoğullama tekniği vb.) en uygun şekilde ayarlayıp yayın yapan gelişmiş bir teknolijidir. Bu sayede spektruma dinamik erişim sağlanmakta ve spektrum kullanım verimliliği artırılmaktadır. İletişim parametreleri aynı spektrum kullanan yakın kaynakların sinyalleri ile en az sinyal girişimini sebep olacak şekilde ayarlanır. Bu ise etraftaki diğer sinyallerin parametrelerinin bilinmesine bağlıdır.

Diğer taraftan istihbarat amaçlı kullanılan sinyallerin izlenmesi ve ortaya çıkarılması güvenlik açısından önemlidir. Bu sinyaller sık sık format değiştiren üstün gizlilik özelliklere sahip olabilirler. Bundan dolayı hızlı ve güvenilir şekilde izlenmeleri ve özelliklerinin belirlenmesi gerekir.

Her ülkenin kendi sahasında spektrumu düzenleyen ve denetleyen yetkili kurumları vardır. Bu kurumların görevlerini icra edebilmeleri sürekli olarak spektrumu izlemeleri ve denetlemelerini gerektirdiğinden dolayı yayındaki sinyallerin özelliklerini bilmeleri çok önemlidir.

Başka bir örnekte günlük hayatımızda kullandığımız cihazlara yönelik olabilir. Bu alıcılar sinyal tanımlama özelliğine sahip tasarlanabilirse farklı yayın özellikleri kullanıldığında kullanım dışı kalmazlar. Örneğin son zamanlarda birçok yerde analog radyo yayınından dijital yayına geçilmesi üzerine milyonlarca radyo kullanım dışı kalmıştır. Bu tanım her ne kadar yazılım tabanlı alıcı (SDRSoftware Defined Radio) tanımına uysada, bizim kastettiğimiz bunun ötesinde yeni yayınları almak için bir yazılım güncellemesine ihtiyaç duymayan ama kendiliğinden öğrenme yaparak uyumlu hale gelen bir alıcıdır. 
Bu bölümde ele alınan gelecek çalışmalar genel anlamda sinyal algıllama, modülasyon tanıma, demodülasyon vb. işlemlerinin DL kullanılarak gerçekleştirildiği çalı̧̧malar olarak değerlendirilebilir. Bu çalı̧̧malardan (T. J. O'Shea \& Corgan, 2016), (West \& O'Shea, 2017), (T. J. O'Shea, Roy, \& Clancy, 2017), (Ramjee et al., 2019) derin öğrenme sahnede başrolü aldıktan sonra modülasyon tanımaya yönelik yapılan ilk çalışmalardan bazılarıdır. (T. J. O'Shea \& Corgan, 2016)'da kullanılan sinyaller GNU radyo kullanılarak oluşturulmuş ve kullanıma açık olarak paylaşılmıştır. Gerçek ortamın sinyal üzerine yapabileceği tüm olumsuz etkiler (frekans seçmeli kanal, AWGN, lokal osilatör frekans kayması, güç geçikme profili) dikkate alınarak sinyaller oluşturulmuştur. Aslında bu, bu problemin çözümünde derin öğrenmeyi cazip yapmıştır, çünkü bu şekilde matematiksel modellemesi çok zor bir kanal yapısı oluşturulmuştur. Dolayısıyla klasik yöntemlerin kullanılma olasılığı zorlaşmıştır. Çalışmanın sonucunda, özellikle düşük sinyal gürültü oranında (SNR) modülasyon tanımada önemli gelişme kaydedilmiştir. Aynı yazarlar (T. J. O'Shea \& Corgan, 2016)'deki modeli dahada geliştirerek oluşturdukları yeni veri seti ve yazılım tabanlı radyo USRP B-210 ile havadan elde ettikleri sinyalleri en çok kullanılan yirmidört farklı modülasyon arasında sınıflandırmayı çalışmışlardır. Neticede en modern sinyal tanıma tekniklerin başarısı elde edilebilmiştir. Bu çalışmanın diğer bir özelliğide sentetik veri ile eğitilerek gerçek veri üzerinde kullanılan ve transfer öğrenim olarak adlandırılan öğrenmenin yanında, havadan alınarak öğrenim yapılan modellede başarılı sonuç elde edilmiş olmasıdır. Modelin tüm detaylarının veri seti ile birlikte paylaşılmasından dolayı bu çalışma araştırmacılar için çok iyi bir referans kaynak olarak değerlendirilebilir. (West \& O'Shea, 2017) verilen çalışma (T. J. O'Shea \& Corgan, 2016)'da çalışılan modelin üzerine kurulmuş ve ek olarak katmanlardan sonra filtreler kullanılmıştır. Optimum model elde edilmeye çalışılmıştır. Bunun için optimum filtre sayısı ve fitre uzunluğu incelenerek, DL'nin diğer uygumalarda başarı gösteren optimum modellerinin test edilmesi amaçlanmıştır. Dört farklı model test edilmiştir. Normal CNN modelinin yalnızca katmanlarının sayısını artırmanın sinyal doğru tanımlama oranına bir katkı yapmadığı ortaya konulmuştur. Artık ağ (RN-Residual Network) mimarisinin kullanıldığı modelde, ilk iki katmandan sonra öğrenmenin durağan seviye vardığı gözlemlenmiştir. Birçok uygulamada önemli katkı yaptığı bilinen başlama (Inception) modulünün kullanımınında bir katkı yapmadığı tespit edilmiştir. Son olarakta zamansal sinyallerin öğrenmesinde sıkça kullanılan ve bir RNN türevi olan uzun kısa süreli hafiza (LSTM - Long short term memory) modeli ile CNN'nin beraber kullanıldığı model incelenmiştir. Bu yapının önceki üç yapıya göre daha iyi sonuç ürettiği belirtilmiştir. Ayrıca CNN'de çokça kullanılan biriktirme (pooling) katmanın bir katkı yapmadığı gözlemlenmiştir. Sonuçta kullanılan sinyallerin gerçek ortam sinyallerden uzak olduğuda belirtilerek, DL modelerinin radyo sinyallerini sınıflarken diğer alanlarda olduğu gibi daha fazla katmanla daha iyi sonuç veremeyebileceğini, dolayısıyla radyo sinyalleri için optimize edilmiş modeller geliştirilmesi gerektiği yargısına varılmıştır. (Ramjee et al., 2019) ana kompanent analizini kullanarak (PCA- Principal Component Analysis) (T. J. O'Shea \& Corgan, 2016)'daki çalışmanın öğretim süresini maliyet fonksiyonunda az bir kayıp karşılığında gerçekleştirmeye çalışmış ve öğretim süresini tahmindeki \%2 kayıpla yirmi kat düşürmeyi başarmıştır. (J. H. Lee et al., 2017) yukarıdaki çalışmalardan biraz daha farklı bir yol izlemiş, öncelikle alınan sinyallerin örneklerinden sinyallin birçok istatiksel özelliğini (en fazla yirimi sekiz) hesaplamış ve bu özelliklere dayanarak beş tür modülasyon arasında sınıflama yapmaya çalışmıştır. DL'den önce özellik belirleyici kullanılmasının DL'nin kullanım amacına aykırı olması ve sistemi daha kompleks hale getirireceği dikkate alınmamıştır. Buna rağmen elde edilen sonuçlar tüm özellikler kullanıldığında BPSK için gayet iyiyken QAM-64 için yetersiz olmuştur. Zhang ve diğ. (2018) konvolüsyonel sinir ağları (CNN) ve uzun kısa süreli bellek (LSTM) kullanarak otomatik modülasyon sınıflama (AMC) önermiş̧ir. Bir önceki çalışmada yapılan sinyal özelliklerin belirlenmesi doğrudan DL modeline bırakılmıştır. CNN'nin zamana bağlı fonksiyonlardaki yetersizliğinden dolayı model, RNN'in bir türevi olan LSTM ile desteklenmiştir. Tek taşıyıcılı onbir farklı modülasyon tipinin sınıflandırılması için insansız have aracının similasyonundan alınan veriler kullanılmıştır. Sonuçta özellik belirleyici ve DL modelinin ayrı kullanıldığı modellemeden veya destek vektör makinesinden (SVM) daha iyi sonuç elde edilmiştir. Çalışmada LSTM ve CNN'nin birbirlerine paralel ve seri bağlanarak test edilmiş ve seri bağlamanın daha iyi sonuç ürettiği belirtilmiştir. Bu durumun (West \& O'Shea, 2017)'te ki tezi doğrular nitelikte olduğunu değerlendiriyoruz. Farklı SNR değerli için tahmin değerleri grafikler halinde sunulmuş ve $10 \mathrm{~dB}$ 'de $\% 80$ 'nin üzerinde tahmin doğruluğana ulaşılmıştır.

Modülasyon tanımlamada mevcut tekniklerden biri olan olabilirlik tabanlı (LB- likelihood based) yöntem optimum sonuçları üretmek için kullanılır. LB'nin alınan sinyalin parametrelerini mükemmel bir şekilde bilmesi gerekir. Bundan dolayı her zaman kullanılabilir değildir. Diğer sistemlerde maksimum güç spektral yoğunluğu (maximum power spectral density), faz, frekans ve genlik standart sapması gibi sinyal özellikleri kullanırlar. Üstelik bu sistemler gürültülü ortamda iyi performans sergilemezler. Bundan dolayı gürültülü ortamlarda modülasyon tanıma önemli olmaktadır. (Mendis, Wei, \& Madanayake, 2016) bunu gerçekleştirmek için yapıllmış bir çalışmadır. Çalışmada spektral korelasyon kullanılarak sinyalin ortalama ve oto korelasyon özellikleri DBN ile işlenerek modülasyon tanımlama yapılmıştır. Araştırmada yarı denetimli bir öğrenim modeli kullanmış, yani modülasyon tanımlaması yapılan sinyal etiketlenerek öğretimde kullanılmıştır. Sonuçta elde edilen similasyonlar önerilen yöntemin $-2 \mathrm{~dB}$ SNR da \%90 doğru karar verme yeteneğine uluştı̆̆ını göstermektedir.

\subsection{Kaynak Paylaşımı}

Kaynak sınırlılığı her alanda olduğu gibi haberleşmede de kendini çok hissettirir ve yapılacak araştırmaların en önemli belirleyicilerinden biridir. Her kullanıcının en azından daha az enerji harcıyarak daha hızlı ve masrafsız bir haberleşme beklenetisini tahmin etmek zor olmayacaktır. Haberleşmedeki kaynaklar genel olarak güç, spektrum ve zaman olarak düşünülebilir. Daha az güç harcayan, spekturumu verimli kullanan, hızlı ve güvenli olan bir haberleşme sistemi oluşturmak ana hedeflerdendir. Gücün verimli kullanımı özelikle bataryaya bağlı mobil cihazlarda önem kazanmaktadır. Sabit cihazların az enerji harcaması ise hem maliyet hemde global dünyanın en büyük sorunlarından biri haline gelen küresel ısınma için önem arz etmektedir. Kullanılan milyonlarca cihazın enerji tüketimin düşürülmesinin veya verimli kullanılmasının çevreye yapacağı pozitif katkı inanılmaz büyüklükte olabilir. Bu açıdan bakıldığında her ne kadar diğer kaynaklar kadar kısıtlı olmasada enerjinin optimum kullanımı diğer kaynakların paylaşımından daha değerli olduğu değerlendirilebilir. Bununla birlikte haberleşmede en önemli ve en kısıtlı ve dolayısıyla en maliyetli kaynak spektrumdur. Dolayısıyla en verimli kullanılması gereken kaynaktır. Örneğin hücresel haberleşme sağlayan şirketler kendilerine verilen kısıtlı bant genişliği için çok büyük ödemeler yaparlar ve bundan dolayı spektrumu çok verimli kullanmak zorundadırlar. Hücresel ağ tasarımları, 
seçilen modülasyon tipi, ışın hüzmesi (beamformer), çoklu erişim yöntemleri kullanma ve benzeri teknolijilerin arkasında genelde bu yatmaktadır. Tüm bu hedeflere ulaşmaya çalışırken servis kalitesindende ödün vermemek gerekmektedir. Dolayısıla ortaya bir optimizasyon problemi çıkmaktadır. Bu optimizasyon için yapılan çalışmalar genelde karmaşık numerik ve yinelemeli algoritmalar içerirken sinyal SNR gibi gerçek zamanlı parametrelerin bilinmesi gerektirir. Örneğin birçok güç paylaşım yaklaşımı matris tersi bulma, tekil değer ayrışımı (SVD- singular value decomposition) hesaplama vb. matematiksel işlemlerin her yinelemede yapılmasını gerektirir ve dolayısıyla gerçek bir sistemde uygulanması en azından harcanan güç ve hesaplama kapasitesi açısından oldukça maliyetlidir. Bu sebeplerden dolayı kompleks olmayan yapılar içeren DL'nin haberleşmede kaynak paylaşımı için kullanılmasına yönelik çalışmalar ilgi odağı haline gelmektedir. Son zamanlarda yapılan bazı çalışmalar kaynak paylaşımlarından bazılarına çözüm önerileri sunmuştur.

(Sun et al., 2017) güç paylaşım optimizasyonun öğrenilebilir olduğunu gösterir. Derin sinir ağları (DNN) kullanarak modern bir yöntem olan ağırlıklı minimum ortalama kare hatası (WMMSE) ile kaynak paylaşımı gerçekleştirmeye çalışılmıştır. Kullanılan veri hem sentetik hemde gerçek verilerden oluşmaktadır. Çalışmada similasyonun yanında teorik hesaplamalarda sunulmuştur. Hesaplamanın kompleksliği ile DNN'de kullanılan katman sayısı arasındaki ilişki ortaya konulmuş ve WMMSE'nin fazla iteresyondan kaynaklanan uzan hesaplama problemini çözmüştür. Bu çalışmalarda modern WMMSE referans alanırak oluştrulan etiketlenmiş veri üzerinden DNN öğrenimi söz konusunu olduğundan DL kapasitesine bir sınırlamada getirilmiştir. Bundan dolayı (Eisen, Zhang, Chamon, Lee, \& Ribeiro, 2018; W. Lee, Kim, \& Cho, 2018) bu sınırlamayı aşmak için uğraşmış ve (W. Lee et al., 2018) CNN ile vericinin güç kontrolünü yaparak enerji veya spektrum verimliliğinden birini maksimum yapmayı modern güç paylaşımı yöntemlerinin ötesinde başarmıştır. (Eisen et al., 2018) ise güç paylaşımı takviyeli derin öğrenme (RDL - reinforcement deep learning) kullanılarak sistem modeli bilinmediğinde çevrim içi yapılan öğrenimle gerçekleştirilmiş ve WMMSE’nin ötesinde bir başarı elde edilebileceği farklı bir yaklaşımla gösterilmiştir.

Pilot olarak adlandırılan ve kanal kestirimi, eşitlemesi, senkranizasyon vb. amaçlar için kullanılan bilgi haberleşmedeki gereksiz bilgi transferine sebep olmakta ve spektrumun kullanım verimliliğini düşürmektedir. Sistemin her kullanıcı için aynı sayıda pilot bilgi kullanmasına gerek olmadığından yola çıkarak, (Kim et al., 2018) kullanıcı konumuna göre kullanılan pilot sayısına karar vermeyi DL ile gerçekleştirmiş̧ir. Model DL'nin giriş verisi olarak kullanıı yerlerini, çıktı olarak pilot atamayı yapmaktadır. Verilen sonuçlara göre teorik üst limitin \%99'na ulaşılmıştır. Spekturumun verimli kullanmanın başka bir yoluda ışın hüzmesi oluşturma (BF- beam forming) ile elektromanyetik dalganın istenilen yöne yönlendirilmesi ile gerçekleştirilebilir. 5G'nin mmWave'i kullanmasında önemli bir unsur olan BF çok fazla sayıda anten içermektedir. Kanalın iyi bilinmediği durumlarda oldukça zor bir mimari olan BF'in DL kullanılarak planlanması (Lin \& Zhu, 2019)'da ele alınmış ve kanal kestiriminden BF oluşturularak verimlilik açısından performans artırımı elde edilmiştir.

Kanalda bilginin hatasız iletilmesi için kodlama yapmak gerekir. Kodlama için eklenen fazladan bilginin spektrumun kullanımı açısından verimliliğgi düşürdüğü değerlendirilir. Bunun yanında kodun uzun olmasıda bilginin hatasız iletimi için önemlidir. Buda alıcıda maliyeti artııır. Çünkü uzun kodlar alıcıda daha kompleks donanımlara gerektiriken harcanan gücüde artırır. Bu açıdan kodun en uygun seçilmesi kaynak paylaşımı başlığı altında değerlendirilebilir. Bu şekildeki kaynak paylaşımınının ise kanal uygulamaları bölümünde incelenmesi uygun görüldü.

\subsection{Kanal Uygulamaları}

Haberleşmenin sağlandığı ortam olarak bilinen kanal tüm tasarımların şeklini belirleyen ana unsurlar biridir. Kanalın özel olduğu durumların aksine paylaşımlı kanallar, özellikle telsiz kanallar tasarımıının en çok dikkat etmesi gereken kanallar olarak adlandırılabilir. Telsiz teknolijinin göstermiş olduğu olağan üstü gelişmeler, mobil haberleşmenin çok yaygınlaşması, nesnelerin internetinin hayatın olağan bir parçası haline gelmesi telsiz kanallarııı üzerindeki yükü çok artırmıştır. Bu kanallar giderek çok daha yoğun kullanılmakta ve karmaşık bir yapıya bürünmektedir. Haberleşmenin kesintisiz, verimli ve en genel tanımıla sağlıklı yapılabilmesi bu kanalların en doğru şekilde kullanılmasına bağlıdır. Kanallar genelde haberleşmeyi olumsuz etkilerler. Bu bozulmayı tespit etmek ve düzeltmek için kodlama kullanılır. Ayrıca kanal etkisi alıcıda kestirilerek ortadan kaldırılmaya ve kanalın sinyal üzerindeki etkisi giderilmeye çalışılır. Bu kestirim genellikle sürekli olmak zorundadır. Bunlar yapılmadığında bir haberleşmden söz etmekte mümkün olamayabilir. Özetle kanalın verimli kullanılması, kodlama ile veride oluşacak hatanın önüne geçilmesi ve alıııda kestirim ile kanalın etkisinin giderilmesi çok önemlidir ve bu amaçlara en iyi şekilde ulaşabilmek için sürekli arayışlar vardır. Tüm bunları optimum olarak yapacak sistemler çok girift matematiksel modellemeler gerektirebilir. Bundan dolayı DL'nin kanala yönelik uygulamaların etkili olabileceği düşünülebilir. Çünkü DL'nin bu durumlarda iyi bir alternatif olduğu bilinmektedir. Buna özellikle milimetrik dalga boyunu kullanacak 5G sistemleri, matematiksel modelleri henüz olmayan kimyasal kanallar örnek verilebilir. Bundan dolayı olarak araştırmacılar DL'yi kullanarak bu problemlere daha iyi çözümler üretmeye çalışmaktadır. Kanalın etkisini anlamak için daha iyi kestirimlerde bulunmak, kanal eşitlemeyi sağlamak, kanalın durumu değerlendirerek daha iyi kodlama ve çözümleme sunmak, frekans ve zaman kaymasının önüne geçmek, kanal kestirimi yapmadan öğretilmiş modeller üzerinden sembol algılama, sembol ve kanal girişimlerinin etkisini düşürmek veya bunlar için klasik yöntemlerin geliştirdiği çözümleri kompleks bir yapı gerektirmeden çözmek için yapılan çalışmaları bu grup da değerlendirildi.

Milimetrik dalga haberleşme sisteminde olduğu gibi moleküler haberleşmede de kanalı matematiksel olarak modellemek çok zordur. Bundan dolayı (Farsad \& Goldsmith, 2018) çift yönlü tekrarlayan sinir ağı (SBRNN) kullanılarak geliştirilen modelle kanal modeli veya bilgisi olmadan bilgi algılama yapılmıştır. Doğrudan iletilen veriden öğrenmeye dayalı bu yöntem her ne kadar kör dedektöre (BD- blind detector) benzesede, $\mathrm{BD}$ tahminlerini varsayılan bir kanal modeline göre yaptığından SBRNN daha iyi bir model olarak kabul edilebilir. Bu çalı̧şa DL'nin matematiksel modellemenin zor olduğu durumlarda çok iyi bir alternatif oluşturduğunu ortaya koymuştur. 
Büyük anlamda 5G ile hayatımıza girecek milimetrik dalga haberleşme (mmWave) kanal kestirimi için çok büyük önbilgi kullanmak zorundadır. Ayrıca Masif MIMO 5G nin en önemli unsurlarından biridir. 5G'nin mmWave'de masif MIMO kullanması ortaya gerçekten olağanüstü bir kanal yapısı çıkarmıştır. (He et al., 2018a) kullanarak bu kanalın kestirimi yönünde yapılan bir çalışmadır. LDAMP şeklinde isimlendirdikleri yöntemde yine kanal matrisi 2D resim olarak model öğretiminde kullanılmış ve mevcut sistemlere göre daha iyi sonuçlar elde edilirken, yöntem analitik çıkarımlarla desteklenmiştir. Ayrıca (X. Li, Alkhateeb, \& Tepedelenlioglu, 2018) kullanılan gereksiz önbilgi boyutunu düşürmek için GAN yapısının kullanıldığı bir çalışma yapılmıștır. Kanal matrisinin haberleşme ortamının bir fonksiyonu olduğundan hareketle, elde edilen kovaryans matris 2D resim gibi değerlendirilip model eğitiminde kullanmış ve eğitilen modelle çok daha az pilot bilgi kullanılarak az bir ortalama kare hatası ile kanal matrisini tahmin etmeyi başarmıştır. Araştırma makalesi (Hao Ye et al., 2018), DL kullanarak OFDM tabanlı sistemler üzerinde kanal kestirimi ve sinyal tespitini araştırmıştır. Model çevrimdışı olarak öğretilmiş ve çevrimiçi olarak test edilmiştir. Çalışmada çevrimdışı ve çevrimiçi kanalın aynı istatistiksel özelliklere sahip olmasına dikkat edilmiştir. Bulunan sonuç yeterli pilot kullanıldığında DL'nin geleneksel sistemlerle karşılaştııılabilir bir performansa sahip olacağını göstermiştir. Sistem LS ve MMSE'den daha iyi performans göstermiştir. Diğer ilginç bir sonuçta, döngüsel ön ek (CP- Cyclic Prefix) kullanmadan sistemin güzel sonuç vermesidir. Bu dolayısıyla spektral verimide artıracaktır. Çalışmada OFDM tabanlı sistemlerde önemli bir sorun olan tepe-ortalama oranı (Peak-to-Average Ratio) da dikkate alınmıştır. Ne yazık ki çalışmada kullanılan optimizasyon teknikleri, istatistiksel kanal modeli ve diğer derin öğrenme modeli detayları ile sunulmamıştır.

DL'in genelde görüntü ve resim tanımak için kullanılan CNN yapısından yararlanmak için birçok çalışmada sinyallerin özellikleri örneğin spektrumları, zaman-frekans cevapları v.b önce resim haline dönüştürülür. (Soltani et al., 2019) öncelikle zaman-freakans cevabı pilot veriler ile tahmin edilip 2D resim haline getirildikten sonra, tahmindeki hatalar gürültü olarak değerlendirilip CNN ait gürültü iyileştirme yönetemleri kullanılarak kanal kestirimi yapılmış ve ideal MMSE'e çok yakın bir kestirim kompleks olmayan bir yapıyla başarılmıştır.

Filtre dizili çoklu taşıyıcı (FBMC - Filter bank multi carrier) gelecek nesil telsiz haberleşme sistemlerinde OFDM'e benzer ama yapısındaki değişiklikle daha iyi spektrum verimliliği sunan ve OFDM'e alternatif olarak sunulan bir çoklu erişim yöntemidir. Bununla birlikte FBMC'de kanal kestirimi yapmak daha zordur. (Cheng et al., 2019) FBMC'de kanal kestirimi DL için formüle edilerek kanal eşitleme yapılmış ve mevcut yöntemlerden daha iyi bir başarı elde edilmiştir.

Alıcıda frekans çevirimi, demodülasyon yapılmadan önce lokal osilatör, dobler v.b etkilerden kaynaklanan frekans, faz ve zaman kaymalarının giderilmesi gerekir. (T. O'Shea, Karra, \& Clancy, 2017) zaman ve frekans kayması için bilinen yöntemlere açıklandıktan sonra DL kullanılarak bu iki senronizasyon simule edilmiş ve performans karşılaştırılması yapılmıştır. Kullanlan modelle düşük SNR'da freakans kaymasında iyi sonuçlar alınmış, zaman kaymasında ise eşleştirme fitresi (MF -match filter) performansı elde edilememiştir.

Kanal kodlama iletilmek istenen bilgiye fazladan eklenen bilgi ile alıcıda kanal etkisinden dolayı oluşabilecek hataları saptama ve/veya düzeltme için kullanılan ve her sayısal haberleşme sisteminin kullanmış olduğu temel bir yöntemdir. Kodlama bir kanalın tam kapasite kullanıla bilmesi için gereklidir. Normalde alıcı gönderilen sinyalin nasıl bir kodlama tekniği kullandığını bilmesi gerekir. Belkide DL'nin kullanıldığı sistemlerde buna gerek kalmayacaktır. Kanal türlerine göre farklı kodların kullanılması, değişen kanal göre kodun özelliğinin değiştirilmesi buna örnek gösterilebilir. Bunun gibi birçok yenilik DL ile kodlamaya kazandırılabilir. (Gruber et al., 2017) DL'nin kod çözümlemede kullanılabileceğini göstermiştir. Bu çalışmaya göre DL sadece basit bir sınıflayıcı değil, bunun ötesinde kodlama algoritmasınıda öğrenebilir bir yapıdır. Hem düzenli hemde rastgele kodları kapsayan bu çalışmada, düzenli kodların kod yapısının genel olarak DL tarafından öğrenilebildiği gösterilirken modelin yalnızca kısa kodlarda uygulanabilirliği belirtilmiştir. Ayrıca bu çalışma DL'nin kodlamada potensiyel ve kısıtlamalarını ortaya koymak için komplekslik ve performansı açısından değerlendirme kriteri içeren analitik çalışma içermektedir. Diğer bir çalışma (H. Ye \& Li, 2017) kanal eşitleme ve kod çözümleme sistemin daha optimum olması için bir arada gerçekleştirilmiş, DL’nin komplike kodlamayı öğrenebileceğine vurgu yapılmış, DL modelinin üstünlükleri kod çözümleme için ön bir bilgiye ihtiyaç olmaması ve dolayısıyla tüm kodlar için evrensel bir yöntem olma potonsiyeli olduğu ayrıca kanal eşitlemeyi ve kod çözümlemeyi bir arada yaparak her iki yapının gerektirmiş olduğu döngüsel hesaplamalı yapıya gerek bırakmaması olarak belirtilmiştir. Bununla birlikte henüz uzun kodlar için bir önbilgi olmadan (kodun özellikleri gibi) çözümleme yapan DL modellerinin geliştirilmesi gerektiğini ifade etmiştir. Bu çalışmadaki yaklaşım (W. Xu, Wu, Ueng, You, \& Zhang, 2017)'de CNN destekli bir kod çözücü ile daha ileri taşınmak amacı ile ele alınmıştır. CNN kanal eşitleme ve gürültü giderimi için kullanıldıktan sonra diğer bir DL modelide çözümleme için kullanılmıştır. (Nachmani et al., 2018)'de önemli bir kod çözme algoritması olan BP (belief propagation) için DL kullanılarak gelişme kaydedilirken BP önemli bir özelliği olan iletilen kodtan bağımsız performans özelliğide korunmuştur. (Nachmani et al., 2018, 2016)'deki model biraz daha geliştirilmiş ve model parametrelerinin sayıs düşürülerek performasta az da olsa iyileşme elde edilmiştir. 


\section{Tartışmalar ve Araştırma Fırsatları}

Derin öğrenmenin haberleşme teknolojilerine olan uygulamaları sınıflandırılarak incelendi. Bazı çalışmaların içeriğinden dolayı birkaç sınıfta değerlendirilmesi mümkünken, daha çok öne çıkan özelliği dikkate alınarak sınıflandırıldı. Yapılan çalışmalardan derin öğrenmenin haberleşmeye yönelik birçok uygulamasının mümkün olduğu gözlemlendi. Bu çalışmalar klasik haberleşme sistemleriyle yarışacak alternatif ortaya koyarken birçok yeni araştırma firsatını da araştırmacılara sunduğu gözlemlendi.

Yeni modeller bölümünde ilgili çalışmalardan örnekler verilerek açıklanan AE modelinin özellikle gelecekteki haberleşme sistemlerinin tasarımlarında yer alacağı öngörüldü. AE ile yapılan çalışmaların pratik uygulamalara taşınması, modern mobil haberleşmenin önemli bir altyapısı olan OFDM teknolojisinde başarı ile kullanılması, OFDM'de önemli olan CP olmaksızın dahi kullanılabilmesi bu öngörüyü doğrulamaktadır. Bununla birlikte AE’nin profesyonel anlamda haberleşme sektöründe kullanılabilmesi için yeni teknolojileride kapsayan uygulamalar genellikle henüz yapılamadığı anlaşıldı. Buna örnek olarak 5G'de kullanılması değerlendirilen ve OFDM'den farklı ortogonal olmayan çoklu erişim tekniği (NOMA) (Vaezi, Schober, Ding, \& Poor, 2018), (Ding et al., 2017) verilebilir. NOMA aynı frekansın aynı anda birçok kullanıcı tarafından kullanılmasını esas almakta ve dolayısıyla sürekli vurgulanan kanal yapısının modellenmesindeki zorluk ortaya çıkmaktadır. Yapılan araştırmalardan AE'nin NOMA ve benzeri birçok yeni nesil mobil teknolijileri için incelenmediği gözlemlendi. Bundan dolayı AE'nin yeni nesil teknolojilere uygulamaları çok geniş bir araştırma sahası oluşturduğu değerlendirildi.

Sinyal algılama ve demodülasyon bölümünde DL'nin birçok farklı uygulamasına değinildi. Çalışmaların başarılı sonuçlar ürettiği gözlemlendi. Araştırmalarda kullanılan sinyallerin farklı veri bankalarından elde edilmesinden dolayı geliştirilen modelleri birbirleriyle kıyaslamak mümkün olmamaktadır. Bu kıyaslamaların sağlıklı yapılabilmesi için bu modellerin aynı sinyaller üzerinde değerlendirilmesi gerekmektedir. Bu değerlendirmeleri yapabilecek birkaç kaynağın dışında açık kaynağa rastlanmadı. Rastlanan kaynaklardaki sinyallerin standartları ise farklılık gösterebilmektedir. Bundan dolayı öncelikle modellerin öğretileceği ve test edileceği sinyallerin özellikleri üzerinde ortak bir fikir birliğine ulaşılması ve araştırmalara yardımcı olacak veri bankaların oluşturulması gerekmektedir. Bu sebeple öğretim için kullanılacak sinyallerin standartlarının belirlenmesi, bu standartlara uygun gerçek sinyallerden oluşan veri bankalarının oluşturulması, bu veri bankaları üzerinde yapılan çalışmaların yeniden değerlendirilerek karşılaştırılması ve iyi sonuç veren modelleri daha da geliştirilmesi birçok açık araştırma alanı oluşturmaktadır.

Kaynak paylaşımları bölümünde DL kullanılarak en modern yöntemlerin başardığı güç paylaşımını yapabilen çalışmalar incelendi. Bununla birlekte yapılan çalışmaların sayıca az olmasından dolayı sağlıklı bir kıyaslama yapılamayacağı değerlendirildi. Geliştirilen modellerin optimum olup olmadığının anlaşılması için yapılacak araştırmalara ihtiyaç olduğu değerlendirildi.

Kanal uygulamaları bölümünde incelenen araştırmalar DL'nin kanal kestiriminde ve eşitlemesinde çok iyi sonuçlar ürettiğini gösterirken kod çözümleme çalışmalarındaki performanslara bakılınca henüz istenen sonuçları üreten modellerin geliştirilemediği görüldü.Yapılan çalışmalar kısa kodlarda kodlama özelliklerini belirten herhangi bir ön bilgi olmadan genel bir kodlama algoritmasını öğrenilebileceğini ortaya koymakla sınırlı kalmaktadır. DL'nin kod çözme uygulamaları başta olmak üzere kanal kestirimi ve eşitleme modellerinin optimize edilmesine yönelik geniş bir araştırma potansiyeli mevcuttur. Yapılan araştırmaların birçoğunun pratik ortamdan uzak olduğu gözlemlenmiştir. İncelenen bazı çalışmalarda ise yazılım tabanlı bir radyo olan USRP kullanılarak gerçek ortamda modeller test edilmiştir. Diğer çalışmalarında bu şekilde gerçekleştirilmesi bu modellerin profesyonelleşmesine yardımcı olurken araştırmaya açık birçok yeni alanı da ortaya koymaktadır.

Yapılabilecek araştırma alanları özetle aşağıdaki başlıklar altında toplanabilir.

1. Yazılım tabanlı alıcılar kullanılarak gerçek sinyallerden oluşan veri bankaların oluşturulup genel üretici lisansı hakkıyla sunulmasi.

2. DL tabanlı alıcıların gerçekleştirilmesi ve ticarileștirilmesi

3. Haberleşmeye uygulanabilir özel DL modellerinin oluşturulması, eğitilmesi ve eğitilmiş model verilerinin paylaşılması.

4. DL tabanlı kod çözücülerin geliştirilmesi ve performanslarının standart kod çözücülerle karşılaştırılması.

5. Kaynak paylaşımı yapan DL modellerinin geliştirilmesi.

6. Kanal kestirimi ve eşitlemesi yapan DL modellerinin geliştirilmesi. 


\section{Sonuçlar}

Bu çalışmada DL'nin haberleşmeye, özellikle telsiz haberleşmeye yönelik uygulamaları alt başlıklar altında incelendi. Derin öğrenmenin çok farklı alanlarda göstermiş olduğu başarıdan dolayı haberleşme alanına dönük araştırmaların artığı ve bu bağlamada birçok çalışmanın yürütülmekte olduğu, buna rağmen bu çalışmaların yeterli sayıda olmadığı sonucuna varıldı. Yapılan çalışmalardan: DL ile kullanılan mevcut sistemlere daha az kompleks daha başarılı olan alternatif sistemlerin yapılabileçeği gözlemlendi. Özelikle çok karmaşık modelleme ve hesap yükü oluşturan sistemlerde DL'nin çok iyi bir alternatif oluşturacağından dolayı tercih edilmesi gerektiği anlaşıldı. Haberleşmede DL'nin kullanımına yönelik araştırmaların önündeki en önemli bir etkenin model öğretiminde kullanılacak standart sinyal veri bankalarının bulunmaması olarak değerlendirildi. Bunun için öncelikle gerçek ortam verilerin (haberleşmede kullanılan sinyaller) belirlenecek standartlara göre oluşturulması ve kullanıma açılması gerektiği sonucuna varıldı. Diğer çok önemli bir etkeninde DL'nin farklı alanlara özel modelleri olmasına karşın, örneğin görsel, ses vb. haberleşmeye özel modellerinin henüz geliştirilmemiş olmamasınından kaynaklandığı anlaşıldı. DL'nin diğer dallarda geçirmiş olduğu evreler bakılınca bu özel modellerin daha çok araştırmacının çalışmalarıyla ortaya çıkaçak doğal bir süreç olduğu değerlendirildi. Çalışmaların sayısını ve kalitesinin etkileyen diğer bir sebebinde haberleşme alanında çalışan araştırmacıların, DL'nin isminin daha çok görüntü, ses tanıma v.b gibi işlemlerle anılmasından dolayı, DL'ye daha az ilgi göstermesinden kaynaklandığı değerlendirildi. İncelenen araştırmalardan DL'nin haberleşmede kullanılan alt sistemlerin birçoğunda uygulanabileceği ve modern tasarımlarla karşılaştırılabilecek sonuçları elde edilebileceği kanısına varıldı. Bu başarının üstelik daha DL'nin haberleşmeye yönelik araştırmaların yeni başladı̆̆ı evrede gerçekleşmesi gerçekten çok büyük bir başarı olarak değerlendirildi. Bundan dolayı araştırma yapabilecek birçok konu olduğu anlaşıldı.

DL'nin haberleşme teknolojilerine günümüze kadar yaptığı katkılardan hiçbiri henüz çığır açıcı nitekte olmamıştır. Bununla birlikte küçük ama çok fazla DL tabanlı çalışma haberleşmenin her kolununda birçok yerde yapılmaktadır. Buna örnek olarak arXiv'de günlük ortalama 1-2 makale yayınlanması verilebilir. DL’in mühendisliğin ve bilgi teknolojilerinin diğer dallarında göstermiş olduğu başarıyı haberleşme teknolojilerinde de bu alanındaki uzmanların DL kullanmasıyla göstereceği açıktır. Son olarak belirtmelidirki yapılan çalışmaların ivmesindeki artış çok yakın zamanda DL'yi pratik olarak birçok haberleşme sisteminim bir parçası olarak görülebileceğini göstermektedir.

\section{Kaynaklar}

Ahmed, K. I., Tabassum, H., \& Hossain, E. (2018). Deep Learning for Radio Resource Allocation in Multi-Cell Networks. CoRR, $a b s / 1808.00667$. Retrieved from http://arxiv.org/abs/1808.00667

Al-Baidhani, A., \& Fan, H. H. (2019). Learning for Detection: A Deep Learning Wireless Communication Receiver Over Rayleigh Fading Channels. 2019 International Conference on Computing, Networking and Communications (ICNC) (pp. 6-10). doi:10.1109/ICCNC.2019.8685517

Amodei, D., Ananthanarayanan, S., Anubhai, R., Bai, J., Battenberg, E., Case, C., Casper, J., et al. (2016). Deep speech 2: End-to-end speech recognition in english and mandarin. International conference on machine learning (pp. 173-182).

Andrychowicz, M., Denil, M., Colmenarejo, S. G., Hoffman, M. W., Pfau, D., Schaul, T., \& Freitas, N. de. (2016). Learning to learn by gradient descent by gradient descent. CoRR, abs/1606.04474. Retrieved from http://arxiv.org/abs/1606.04474

Arnold, M., Dörner, S., Cammerer, S., Yan, S., Hoydis, J., \& Brink, S. ten. (2019). Enabling FDD Massive MIMO through Deep Learning-based Channel Prediction. CoRR, abs/1901.03664.

Ba, J. L., Kiros, J. R., \& Hinton, G. E. (2016). Layer normalization. arXiv preprint arXiv:1607.06450.

Bourtsoulatze, E., Kurka, D. B., \& Gunduz, D. (2018). Deep joint source-channel coding for wireless image transmission. arXiv preprint arXiv: 1809.01733

Chen, D., \& Laneman, J. N. (2006). Modulation and demodulation for cooperative diversity in wireless systems. IEEE Transactions on Wireless Communications, 5(7), 1785-1794.

Cheng, X., Liu, D., Wang, C., Yan, S., \& Zhu, Z. (2019). Deep Learning based Channel Estimation and Equalization Scheme for FBMC/OQAM Systems. IEEE Wireless Communications Letters, 1-1. doi:10.1109/LWC.2019.2898437

Chikha, W. B., Dayoub, I., Hamouda, W., \& Attia, R. (2014). Modulation Recognition for MIMO Relaying Broadcast Channels with Direct Link. IEEE Wireless Communications Letters, 3(1), 50-53. doi:10.1109/WCL.2013.111113.130655

Corlay, V., Boutros, J. J., Ciblat, P., \& Brunel, L. (2018). Multilevel MIMO Detection with Deep Learning. 2018 52nd Asilomar Conference on Signals, Systems, and Computers (pp. 1805-1809). doi:10.1109/ACSSC.2018.8645519

Diamandis, T. (2017). Survey on Deep Learning Techniques for Wireless Communications.

Ding, Z., Lei, X., Karagiannidis, G. K., Schober, R., Yuan, J., \& Bhargava, V. K. (2017). A survey on non-orthogonal multiple access for $5 \mathrm{G}$ networks: Research challenges and future trends. IEEE Journal on Selected Areas in Communications, 35(10), $2181-2195$.

Dörner, S., Cammerer, S., Hoydis, J., \& Brink, S. ten. (2018). Deep learning based communication over the air. IEEE Journal of Selected Topics in Signal Processing, 12(1), 132-143.

Eisen, M., Zhang, C., Chamon, L. F. O., Lee, D. D., \& Ribeiro, A. (2018). Online Deep Learning in Wireless Communication Systems. 2018 52nd Asilomar Conference on Signals, Systems, and Computers (pp. 1289-1293). doi:10.1109/ACSSC.2018.8645312

Elbaz, D., \& Zibulevsky, M. (2018). End to End Deep Neural Network Frequency Demodulation of Speech Signals. Future of Information and Communication Conference (pp. 1-11). Springer.

Farsad, N., \& Goldsmith, A. (2018). Neural network detection of data sequences in communication systems. arXiv preprint arXiv:1802.02046. 
Felix, A., Cammerer, S., Dörner, S., Hoydis, J., \& Brink, S. ten. (2018). OFDM-Autoencoder for End-to-End Learning of Communications Systems. 2018 IEEE 19th International Workshop on Signal Processing Advances in Wireless Communications (SPAWC), 1-5.

Fujihashi, T., Koike-Akino, T., Watanabe, T., \& Orlik, P. V. (2018). Nonlinear Equalization with Deep Learning for Multi-Purpose Visual MIMO Communications. 2018 IEEE International Conference on Communications (ICC) (pp. 1-6). doi:10.1109/ICC.2018.8422544

Goodfellow, I., Bengio, Y., Courville, A., \& Bengio, Y. (2016). Deep learning (Vol. 1). MIT press Cambridge.

Goodfellow, I., Pouget-Abadie, J., Mirza, M., Xu, B., Warde-Farley, D., Ozair, S., Courville, A., et al. (2014). Generative adversarial nets. Advances in neural information processing systems (pp. 2672-2680).

Graves, A., \& Jaitly, N. (2014). Towards end-to-end speech recognition with recurrent neural networks. International Conference on Machine Learning (pp. 1764-1772).

Gruber, T., Cammerer, S., Hoydis, J., \& Brink, S. t. (2017). On deep learning-based channel decoding. 201751 st Annual Conference on Information Sciences and Systems (CISS) (pp. 1-6). doi:10.1109/CISS.2017.7926071

Guo, C., Liang, L., \& Li, G. Y. (2019). Resource Allocation for V2X Communications: A Large Deviation Theory Perspective. IEEE Wireless Communications Letters, 1-1. doi:10.1109/LWC.2019.2908165

Han, S., Mao, H., \& Dally, W. J. (2016). Deep Compression: Compressing Deep Neural Network with Pruning, Trained Quantization and Huffman Coding. CoRR, abs/1510.00149.

He, H., Wen, C., Jin, S., \& Li, G. Y. (2018a). A Model-Driven Deep Learning Network for MIMO Detection. 2018 IEEE Global Conference on Signal and Information Processing (GlobalSIP) (pp. 584-588). doi:10.1109/GlobalSIP.2018.8646357

He, H., Wen, C., Jin, S., \& Li, G. Y. (2018b). Deep Learning-Based Channel Estimation for Beamspace mmWave Massive MIMO Systems. IEEE Wireless Communications Letters, 7(5), 852-855. doi:10.1109/LWC.2018.2832128

Hinton, G., Deng, L., Yu, D., Dahl, G., Mohamed, A., Jaitly, N., Senior, A., et al. (2012). Deep neural networks for acoustic modeling in speech recognition. IEEE Signal processing magazine, 29.

Hinton, G. E., Osindero, S., \& Teh, Y.-W. (2006). A fast learning algorithm for deep belief nets. Neural computation, $18(7), 1527-1554$.

Hinton, G. E., \& Salakhutdinov, R. R. (2006). Reducing the dimensionality of data with neural networks. science, 313(5786), 504-507.

Hinton, G. E., Srivastava, N., Krizhevsky, A., Sutskever, I., \& Salakhutdinov, R. R. (2012). Improving neural networks by preventing co-adaptation of feature detectors. arXiv preprint arXiv:1207.0580.

Ibnkahla, M. (2000). Applications of neural networks to digital communications-a survey. Signal processing, 80(7), $1185-1215$.

Ioffe, S., \& Szegedy, C. (2015). Batch normalization: Accelerating deep network training by reducing internal covariate shift. arXiv preprint arXiv: 1502.03167 .

Jaderberg, M., Czarnecki, W. M., Osindero, S., Vinyals, O., Graves, A., Silver, D., \& Kavukcuoglu, K. (2017). Decoupled neural interfaces using synthetic gradients. Proceedings of the 34th International Conference on Machine Learning-Volume 70 (pp. 16271635). JMLR. org.

Jia, Z., Cheng, W., \& Zhang, H. (2019). A Partial Learning Based Detection Scheme for Massive MIMO. IEEE Wireless Communications Letters, 1-1. doi:10.1109/1wc.2019.2909019

Jiang, Z., Chen, S., Molisch, A. F., Vannithamby, R., Zhou, S., \& Niu, Z. (2019). Exploiting Wireless Channel State Information Structures Beyond Linear Correlations: A Deep Learning Approach. IEEE Communications Magazine, 57, $28-34$.

Jiang, Z., He, Z., Chen, S., Molisch, A. F., Zhou, S., \& Niu, Z. (2018). Inferring Remote Channel State Information: Cramér-Rae Lower Bound and Deep Learning Implementation. 2018 IEEE Global Communications Conference (GLOBECOM), 1-7.

Kang, J., Chun, C., \& Kim, I. (2018). Deep-Learning-Based Channel Estimation for Wireless Energy Transfer. IEEE Communications Letters, 22(11), 2310-2313. doi:10.1109/LCOMM.2018.2871442

Karanov, B., Lavery, D., Bayvel, P., \& Schmalen, L. (2019). End-to-End Optimized Transmission over Dispersive Intensity-Modulated Channels Using Bidirectional Recurrent Neural Networks. CoRR, abs/1901.08570.

Kim, K., Lee, J., \& Choi, J. (2018). Deep Learning Based Pilot Allocation Scheme (DL-PAS) for 5G Massive MIMO System. IEEE Communications Letters, 22(4), 828-831. doi:10.1109/LCOMM.2018.2803054

Kingma, D. P., \& Ba, J. (2014). Adam: A method for stochastic optimization. arXiv preprint arXiv:1412.6980.

Krizhevsky, A., Sutskever, I., \& Hinton, G. E. (2012). Imagenet classification with deep convolutional neural networks. Advances in neural information processing systems (pp. 1097-1105).

Laura Brink Anant Sahai, E. Ed. John Wawrzynek. (2018). Deep Networks for Equalization in Communications (No. UCB/EECS-2018177). Electrical Engineering and Computer Sciences University of California at Berkeley. Retrieved from https://www2.eecs.berkeley.edu/Pubs/TechRpts/2018/EECS-2018-177.pdf

LeCun, Y., Bengio, Y., \& Hinton, G. (2015). Deep learning. nature, 521(7553), 436.

Lee, J. H., Kim, J., Kim, B., Yoon, D., \& Choi, J. W. (2017). Robust Automatic Modulation Classification Technique for Fading Channels via Deep Neural Network. Entropy, 19, 454.

Lee, W., Kim, M., \& Cho, D. (2018). Deep Power Control: Transmit Power Control Scheme Based on Convolutional Neural Network. IEEE Communications Letters, 22(6), 1276-1279. doi:10.1109/LCOMM.2018.2825444

Li, H., Gao, H., Lv, T., \& Lu, Y. (2018). Deep Q-Learning Based Dynamic Resource Allocation for Self-Powered Ultra-Dense Networks. 2018 IEEE International Conference on Communications Workshops (ICC Workshops) (pp. 1-6). doi:10.1109/ICCW.2018.8403505

Li, J., Gao, H., Lv, T., \& Lu, Y. (2018). Deep reinforcement learning based computation offloading and resource allocation for MEC. 2018 IEEE Wireless Communications and Networking Conference (WCNC) (pp. 1-6). doi:10.1109/WCNC.2018.8377343

Li, X., Alkhateeb, A., \& Tepedelenlioglu, C. (2018). Generative adversarial estimation of channel covariance in vehicular millimeter wave systems. 2018 52nd Asilomar Conference on Signals, Systems, and Computers (pp. 1572-1576). IEEE.

Lin, T., \& Zhu, Y. (2019). Beamforming Design for Large-Scale Antenna Arrays Using Deep Learning. 
Liu, X., Yang, D., \& Gamal, A. E. (2017). Deep neural network architectures for modulation classification. 2017 51st Asilomar Conference on Signals, Systems, and Computers, 915-919.

Mendis, G. J., Wei, J., \& Madanayake, A. (2016). Deep learning-based automated modulation classification for cognitive radio. 2016 IEEE International Conference on Communication Systems (ICCS) (pp. 1-6). doi:10.1109/ICCS.2016.7833571

Mendis, G. J., Wei, J., \& Madanayake, A. (2019). Deep Learning based Radio-Signal Identification with Hardware Design. IEEE Transactions on Aerospace and Electronic Systems, 1-1. doi:10.1109/TAES.2019.2891155

Mnih, V., Kavukcuoglu, K., Silver, D., Rusu, A. A., Veness, J., Bellemare, M. G., Graves, A., et al. (2015). Human-level control through deep reinforcement learning. Nature, 518, 529-533.

Mohammad, A. S., Reddy, N., James, F., \& Beard, C. (2018). Demodulation of faded wireless signals using deep convolutional neural networks. 2018 IEEE 8th Annual Computing and Communication Workshop and Conference (CCWC) (pp. 969-975). IEEE.

Mohammad, U., \& Sorour, S. (2018). Adaptive Task Allocation for Mobile Edge Learning. arXiv preprint arXiv:1811.03748.

Nachmani, E., Be'ery, Y., \& Burshtein, D. (2016). Learning to decode linear codes using deep learning. 2016 54th Annual Allerton Conference on Communication, Control, and Computing (Allerton) (pp. 341-346). doi:10.1109/ALLERTON.2016.7852251

Nachmani, E., Marciano, E., Lugosch, L., Gross, W. J., Burshtein, D., \& Be'ery, Y. (2018). Deep Learning Methods for Improved Decoding of Linear Codes. IEEE Journal of Selected Topics in Signal Processing, 12(1), 119-131. doi:10.1109/JSTSP.2017.2788405

Nasir, Y. S., \& Guo, D. (2018). Deep reinforcement learning for distributed dynamic power allocation in wireless networks. arXiv preprint arXiv: 1808.00490.

O’Shea, T. J., \& Corgan, J. (2016). Convolutional Radio Modulation Recognition Networks. CoRR, abs/1602.04105. Retrieved from http://arxiv.org/abs/1602.04105

O'Shea, T. J., Corgan, J., \& Clancy, T. C. (n.d.). Unsupervised Representation Learning of Structured Radio Communication Signals.

O'Shea, T. J., Erpek, T., \& Clancy, T. C. (2017). Deep learning based MIMO communications. arXiv preprint arXiv:1707.07980.

O’Shea, T. J., Erpek, T., \& Clancy, T. C. (n.d.). Deep Learning Based MIMO Communications.

O'Shea, T. J., \& Hoydis, J. (2017). An introduction to machine learning communications systems. arXiv preprint, 1702.

O'Shea, T. J., Karra, K., \& Clancy, T. C. (2016). Learning to communicate: Channel auto-encoders, domain specific regularizers, and attention. Signal Processing and Information Technology (ISSPIT), 2016 IEEE International Symposium on (pp. 223-228). IEEE.

O'Shea, T. J., Roy, T., \& Clancy, T. C. (2017). Over the Air Deep Learning Based Radio Signal Classification. CoRR, abs/1712.04578. Retrieved from http://arxiv.org/abs/1712.04578

O'Shea, T. J., Roy, T., \& West, N. (2018). Approximating the Void: Learning Stochastic Channel Models from Observation with Variational Generative Adversarial Networks. CoRR, abs/1805.06350.

O’Shea, T. J., Roy, T., West, N., \& Hilburn, B. C. (2018). Physical Layer Communications System Design Over-the-Air Using Adversarial Networks. arXiv preprint arXiv:1803.03145.

O’Shea, T., Karra, K., \& Clancy, T. C. (2017). Learning approximate neural estimators for wireless channel state information. 2017 IEEE 27th International Workshop on Machine Learning for Signal Processing (MLSP) (pp. 1-7). IEEE.

Ramjee, S., Ju, S., Yang, D., Liu, X., Gamal, A. E., \& Eldar, Y. C. (2019). Fast Deep Learning for Automatic Modulation Classification. CoRR, abs/1901.05850.

Reddy, Y. B. (2006). Reinforcement Learning for Resource Allocation in Multiuser OFDM Systems. ICWN (pp. 78-83).

Sak, H., Senior, A., Rao, K., \& Beaufays, F. (2015). Fast and accurate recurrent neural network acoustic models for speech recognition. arXiv preprint arXiv:1507.06947.

Samuel, N., Diskin, T., \& Wiesel, A. (2017). Deep MIMO detection. 2017 IEEE 18th International Workshop on Signal Processing Advances in Wireless Communications (SPAWC) (pp. 1-5). doi:10.1109/SPAWC.2017.8227772

Sanguinetti, L., Zappone, A., \& Debbah, M. (2018). Deep Learning Power Allocation in Massive MIMO. 2018 52nd Asilomar Conference on Signals, Systems, and Computers, 1257-1261.

Saud Mobark Aldossari, K.-C. C. (2019). Machine Learning for Wireless Communication Channel Modeling: An Overview. Wireless Personal Communications, 1.

Shen, Y., Shi, Y., Zhang, J., \& Letaief, K. B. (2018). LORA: Learning to Optimize for Resource Allocation in Wireless Networks with Few Training Samples. arXiv preprint arXiv:1812.07998.

Silver, D., Huang, A., Maddison, C. J., Guez, A., Sifre, L., Driessche, G. van den, Schrittwieser, J., et al. (2016). Mastering the game of Go with deep neural networks and tree search. Nature, 529, 484-489.

Soltani, M., Pourahmadi, V., Mirzaei, A., \& Sheikhzadeh, H. (2019). Deep Learning-Based Channel Estimation. IEEE Communications Letters.

Sorokina, M., \& Turitsyn, S. (2014). Regeneration limit of classical Shannon capacity. Nature communications, 5, 3861.

Srivastava, N., Hinton, G., Krizhevsky, A., Sutskever, I., \& Salakhutdinov, R. (2014). Dropout: a simple way to prevent neural networks from overfitting. The Journal of Machine Learning Research, 15(1), 1929-1958.

Sun, H., Chen, X., Shi, Q., Hong, M., Fu, X., \& Sidiropoulos, N. D. (2017). Learning to optimize: Training deep neural networks for wireless resource management. 2017 IEEE 18th International Workshop on Signal Processing Advances in Wireless Communications (SPAWC) (pp. 1-6). doi:10.1109/SPAWC.2017.8227766

Szegedy, C., Liu, W., Jia, Y., Sermanet, P., Reed, S., Anguelov, D., Erhan, D., et al. (2015). Going deeper with convolutions. Proceedings of the IEEE conference on computer vision and pattern recognition (pp. 1-9).

Vaezi, M., Schober, R., Ding, Z., \& Poor, H. V. (2018). Non-orthogonal multiple access: Common myths and critical questions. arXiv preprint arXiv:1809.07224.

Wang, H., Wu, Z., Ma, S., Lu, S., Zhang, H., Ding, G., \& Li, S. (2019). Deep Learning for Signal Demodulation in Physical Layer Wireless Communications: Prototype Platform, Open Dataset, and Analytics. IEEE Access, 7, 30792-30801. 
Wang, J., Zhao, L., Liu, J., \& Kato, N. (2019). Smart Resource Allocation for Mobile Edge Computing: A Deep Reinforcement Learning Approach. IEEE Transactions on Emerging Topics in Computing, 1-1. doi:10.1109/TETC.2019.2902661

West, N. E., \& O'Shea, T. J. (2017). Deep Architectures for Modulation Recognition. CoRR, abs/1703.09197. Retrieved from http://arxiv.org/abs/1703.09197

Wu, C., Zhang, Li, Q., Fu, Z., Zhu, W., \& Zhang, Y. (2019). Enabling Flexible Resource Allocation in Mobile Deep Learning Systems. IEEE Transactions on Parallel and Distributed Systems, 30(2), 346-360. doi:10.1109/TPDS.2018.2865359

Xiong, W., Droppo, J., Huang, X., Seide, F., Seltzer, M., Stolcke, A., Yu, D., et al. (2016). Achieving human parity in conversational speech recognition. arXiv preprint arXiv:1610.05256.

Xu, S., Liu, P., Wang, R., \& Panwar, S. S. (2018). Realtime Scheduling and Power Allocation Using Deep Neural Networks. CoRR, abs/1811.07416.

Xu, W., Wu, Z., Ueng, Y., You, X., \& Zhang, C. (2017). Improved polar decoder based on deep learning. 2017 IEEE International Workshop on Signal Processing Systems (SiPS) (pp. 1-6). doi:10.1109/SiPS.2017.8109997

Xu, Z., Wang, Y., Tang, J., Wang, J., \& Gursoy, M. C. (2017). A deep reinforcement learning based framework for power-efficient resource allocation in cloud RANs. Communications (ICC), 2017 IEEE International Conference on (pp. 1-6). IEEE.

Yang, T., ü, Y., Gursoy, M. C., Schmeink, A., \& Mathar, R. (2018). Deep Reinforcement Learning based Resource Allocation in Low Latency Edge Computing Networks. 2018 15th International Symposium on Wireless Communication Systems (ISWCS) (pp. 1-5). doi:10.1109/ISWCS.2018.8491089

Yang, Y., Gao, F., Ma, X., \& Zhang, S. (2019). Deep Learning-Based Channel Estimation for Doubly Selective Fading Channels. IEEE Access, 7, 36579-36589. doi:10.1109/ACCESS.2019.2901066

Yang, Y., Li, Y., Zhang, W., Qin, F., Zhu, P., \& Wang, C. (2019). Generative-Adversarial-Network-Based Wireless Channel Modeling: Challenges and Opportunities. IEEE Communications Magazine, 57(3), 22-27. doi:10.1109/MCOM.2019.1800635

Yashashwi, K., Sethi, A., \& Chaporkar, P. (2019). A Learnable Distortion Correction Module for Modulation Recognition. IEEE Wireless Communications Letters, 8(1), 77-80. doi:10.1109/LWC.2018.2855749

Ye, H., \& Li, G. Y. (2017). Initial Results on Deep Learning for Joint Channel Equalization and Decoding. 2017 IEEE 86th Vehicular Technology Conference (VTC-Fall) (pp. 1-5). doi:10.1109/VTCFall.2017.8288419

Ye, H., Li, G. Y., \& Juang, B.-H. (2018). Power of deep learning for channel estimation and signal detection in OFDM systems. IEEE Wireless Communications Letters, 7(1), 114-117.

Ye, H., Li, Y. G., \& Juang, B. F. (2019). Deep Reinforcement Learning for Resource Allocation in V2V Communications. IEEE Transactions on Vehicular Technology, 1-1. doi:10.1109/TVT.2019.2897134

Zhang, D., Ding, W., Zhang, B., Xie, C., Li, H., Liu, C., \& Han, J. (2018). Automatic Modulation Classification Based on Deep Learning for Unmanned Aerial Vehicles. Sensors.

Zhao, N., Liang, Y., Niyato, D., Pei, Y., \& Jiang, Y. (2018). Deep Reinforcement Learning for User Association and Resource Allocation in Heterogeneous Networks. 2018 IEEE Global Communications Conference (GLOBECOM) (pp. 1-6). doi:10.1109/GLOCOM.2018.8647611

Zhou, Y., Fadlullah, Z. M., Mao, B., \& Kato, N. (2018). A Deep-Learning-Based Radio Resource Assignment Technique for 5G Ultra Dense Networks. IEEE Network, 32(6), 28-34. 